\title{
Introduction to the Special Issue: Economic and Policy Implications in K-12 African American Education
}

\author{
Shawn Anthony Robinson ${ }^{1} \cdot$ Richard McGregory $\mathrm{Jr}^{2}$
}

Published online: 23 May 2020

(C) Springer Nature Switzerland AG 2020

Educational access and success within the K-12 educational system, and how these factors impact the economic progression of African American families and communities, have been at the forefront of policy discussions for more than a century.

The three articles in this special issue respond to pernicious and persistent educational inequities in the learning experiences and educational achievement of African Americans. The papers were submitted to the Journal of Economics, Race, and Policy (without guarantee of publication), went through the regular peer review process, and were revised in response to comments by anonymous reviewers.

In this issue, Ramsay-Jordan's analysis titled "Hidden Figures: How Pecuniary Influences Help Shape STEM Experiences for Black Students in Grades K-12" focused on increasing participation of K-12 African Americans in STEM educational programming. Ramsay-Jordan's article examined how socioeconomic status and inequitable funding have slowed efforts toward increased participation of African American students in STEM programming, which has widened gaps between African Americans and their white peers in terms of access and learning.

In their analysis titled, "Do Racial Disparities Exist in the Labor Market for Educators?" Wilson, Dantzler, Evans, and McGregory used Current Population Survey data to investigate the wages of K-20 educators in order to test competing hypotheses about racial disparities in the US educator labor market. Findings indicate that students may lack access to African American teachers due to disparities in education labor market experiences. The authors offer policy recommendations which address the national issue of mitigating the underrepresentation of African American teachers.

The analysis from Rivera Rodas titled "The Reversal of Mount Laurel's Regional Contribution Agreements and the Impact on White-Black Academic Achievement Gaps across New Jersey: 2008-2014" raises awareness of the connection between affordable housing and academic achievement gaps for New Jersey school districts which were formerly Regional Contribution Agreements (RCAs) receiving districts. RCAs typically involve communities with positive job growth paying to transfer the costs and responsibilities of building of affordable housing to other communities. The study found a positive correlation between changes in the number of affordable housing unit changes and differential learning outcomes among African American and white students.

We are grateful to all the authors for their efforts and to the referees for their frank assessments of the articles considered for this issue. We also wish to thank Gary A. Hoover for his guidance as we assembled this issue.

Publisher's note Springer Nature remains neutral with regard to jurisdictional claims in published maps and institutional affiliations.
Shawn Anthony Robinson

srobinson25@wisc.edu

Richard McGregory, Jr

rcmcgregory@yahoo.com

1 Wisconsin's Equity and Inclusion Laboratory, University of Wisconsin-Madison, Madison, WI, USA

2 Office of National Black Student Union, Whitewater, WI 53190 , USA 